\title{
Why Simpler Arguments are Better
}

\author{
Moti Mizrahi \\ Florida Institute of Technology \\ Forthcoming in Argumentation
}

\begin{abstract}
In this paper, I argue that, other things being equal, simpler arguments are better. In other words, I argue that, other things being equal, it is rational to prefer simpler arguments over less simple ones. I sketch three arguments in support of this claim: an argument from mathematical proofs, an argument from scientific theories, and an argument from the conjunction rule.
\end{abstract}

Keywords: argument; deduction; elegance; explanation; induction; parsimony; proof; simplicity; theory

\section{Introduction}

It appears that many philosophers are often bedazzled by complex arguments. They admire the depth and complexity of a philosopher's arguments even though, when pressed, they might admit that the philosopher's arguments are often not of the highest argumentative standard. This is the impression one gets when it is said with approval of philosophy in general that it is "difficult" (Protevi 2001, p. 150), "hard" (Craig 2002, p. 100), or "complicated" (LeBon 1999, p. 17), and of particular philosophers, like Nietzsche and Hegel, that their "philosophy [is] hard to understand" (Danto 2005, p. 79) or "difficult" (Wood 2004, p. 197). ${ }^{1}$ As Kelly (2011, p. 106) puts it:

To this day, great philosophers who embraced strange conclusions are praised in eulogies for their willingness to follow the argument where it leads, and the ideal is mentioned in faculty handbooks in the context of discussions of academic freedom.

I think that this is a mistake. That is to say, I think that, instead of admiring complexity in philosophical argumentation, we should prefer simplicity. In this paper, then, I argue that, other things being equal, simpler arguments are better. In other words, if our goal in putting forth arguments is truth, or at least rational persuasion, then we should prefer simpler arguments, other things being equal. ${ }^{2}$

\footnotetext{
${ }^{1}$ It is also worth noting that, against the attempt by some, like Simon Blackburn, to make philosophy public, i.e., more accessible to a general audience, others have argued that "philosophy is supposed to be difficult" (http://www.theguardian.com/books/booksblog/2011/feb/25/philosophy-technical-everyday-english).

${ }^{2}$ On the use of arguments as tools of rational persuasion, see Hitchcock (2007), Johnson (2000), and Walton (1996). The notion of rational persuasion is supposed to exclude other forms of persuasion, such as threats and other kinds of blackmail. This is also meant to deal with alleged counterexamples where it seems rational to prefer complex
} 
As far as arguments are concerned, it is common practice to distinguish between at least two kinds: deductive and inductive (i.e., non-deductive) arguments (see, e.g., Copi and Cohen 2005; Sinnott-Armstrong and Fogelin 2010). The premises of a valid deductive argument, if true, necessitate the truth of the conclusion. Hence, valid deductive arguments can be represented as follows:

\section{(Deduction) IF $\left\{\right.$ Premise $_{1}$, Premise $_{2}, \ldots$, Premise $\left._{n}\right\}$ THEN necessarily $\{\text { Conclusion }\}^{-}$}

The premises of a strong inductive argument, if true, make the truth of the conclusion more probable, i.e., $\mathrm{P}$ (Conclusion | Premises $)>\mathrm{P}(\neg$ Conclusion | Premises $)$, but not guaranteed. ${ }^{3}$ Hence, strong inductive arguments can be represented as follows ${ }^{4}$ :

\section{(Induction) IF $\left\{\right.$ Premise $_{1}$, Premise $_{2}, \ldots$, Premise $\left._{n}\right\}$ THEN probably $\{\text { Conclusion }\}^{-}$}

With these basic characterizations of deductive and inductive arguments, I will argue in what follows that, of two competing arguments (either deductive or inductive), we should prefer the simpler one, other things being equal.

Here is how I plan to proceed. In Section 2, I discuss two varieties of simplicity, namely syntactic simplicity (or elegance) and ontological simplicity (or parsimony). In Section 3, I sketch an argument from mathematical proofs for the claim that, other things being equal, simpler arguments are better. In Section 4, I sketch an argument from scientific theories for the claim that, other things being equal, simpler arguments are better. In Section 5, I sketch an argument from the conjunction rule for the claim that, other things being equal, simpler arguments are better.

\section{Two varieties of simplicity}

Before I sketch my arguments for the claim that, other things being equal, simpler arguments are better, a few clarifications are in order. More specifically, I need to explain in more detail what is meant by simplicity. Philosophers usually identify two varieties of simplicity. In this section, I discuss these two varieties of simplicity. I am not concerned with the justification of simplicity principles. ${ }^{5}$ Rather, I am concerned with simplicity as a theoretical virtue of arguments. ${ }^{6}$

arguments. For example, suppose that an eccentric billionaire offers a cash prize for "Most Complex Argument." In this case, it seems rational to prefer more complex arguments, not for the sake of truth and/or rational persuasion, but rather for the sake of winning a cash prize. Thanks to Andrew Aberdein for this point.

${ }^{3}$ Discussing the various concepts of probability and their interpretations is beyond the scope of this paper. For a useful overview, see Mellor (2005).

\footnotetext{
${ }^{4}$ Note that this characterization of inductive arguments is broad enough to include non-deductive arguments like abductive arguments (or inferences to the best explanation) and conductive arguments (Govier 2010). For a useful overview, see McKeon (2013).

${ }^{5}$ See, e.g., Sober (1988) and (1994). Sober argues that appeals to simplicity are local rather than global, i.e., they depend on local background assumptions and context for their rational justification.
} 


\section{2a. Syntactic simplicity}

According to Sober (1988), considerations of simplicity play a role in the so-called "curve-fitting problem.” To use Sober's (1998) example, suppose that scientists want to discover general relations that might hold between independent variable $x$ and dependent variable $y$. They gather the following set of observations, depicted as points in Figure 1 (adapted from Sober 1998).

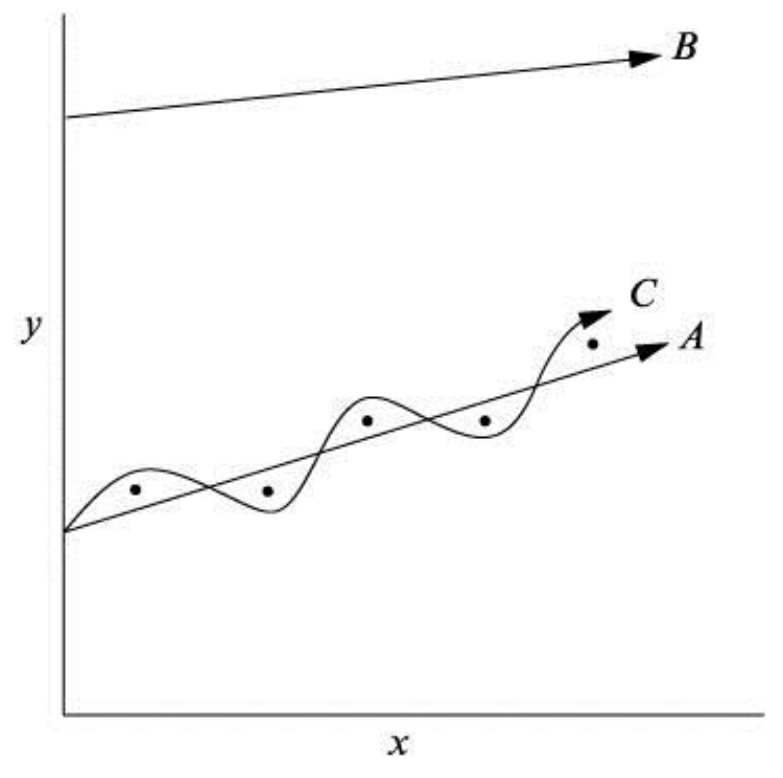

Figure 1. Curve-fitting and goodness-of-fit adapted from Sober (1998).

They then evaluate competing hypotheses, $A, B$, and $C$, depicted as curves in Figure 1. In cases such as this one, given that the possibility of error is taken into account, the standard scientific practice, according to Sober (1998, p. 781), is to use the notion of "goodness-of-fit." For example, for each data point on curve $A$, the scientists compute the squared distance from the observed $y$-value to the $y$-value that curve $A$ predicts. In this way, the "sum of squares" (SOS)

\footnotetext{
${ }^{6}$ In this paper, I talk about simplicity as a theoretical virtue of arguments in much the same way that simplicity is taken to be a theoretical virtue of mathematical proofs and scientific theories. See, e.g., Baker (2011), Glynn (2010), and Sober (2001). On the virtues of arguers, rather than arguments, see Aberdein (2010).
} 
measures how far the curve is from the data points. If SOS measures how well the data support the curve in question, then the data support curve $A$ better than they support curve $B$. As Sober (1998, p. 781) puts it:

Curves that are close to the data are more likely, in the technical sense defined by R. A. Fisher (1925). Curve $A$ is more likely than Curve $B$ (given standard assumptions about the probability of error) because $A$ confers on the data a higher probability than $B$ does: $\mathrm{P}($ Data $\mid$ Curve $A)>\mathrm{P}($ Data $\mid$ Curve $B){ }^{7}$

At this point, simplicity becomes relevant, since curve $A$ and curve $C$ have the same SOS values. If the scientists are guided by considerations of simplicity, they will choose curve $A$ over curve $C$, for curve $A$ is smooth, whereas curve $C$ is bumpy. As Sober (1998, p. 781) puts it, "Curve $A$ seems more simple." In other words, curve $A$ posits a simpler relationship between variables $x$ and $y$ than curve $C$ does, and is thus preferable to curve $C{ }^{8}$

This variety of simplicity, then, has to do with the number and complexity of hypotheses. As Baker (2011), puts it, "Syntactic simplicity, or elegance, measures the number and conciseness of the theory's basic principles." More explicitly:

(Elegance) Other things being equal, if $T_{1}$ is more syntactically simple than $T_{2}$, then it is rational to prefer $T_{1}$ over $T_{2}$.

As Gauch (2003, p. 270) notes, this is an epistemological conception of simplicity.

\section{2b. Ontological simplicity}

Another variety of simplicity has to do with the number and complexity of postulated entities rather than hypotheses. Ockham's razor is perhaps the most famous formulation of this variety of simplicity.

(Ockham's razor) Entities are not to be multiplied beyond necessity.

As Gauch (2003, p. 270) notes, this is an ontological conception of simplicity, which is also known as the principle of parsimony. According to the principle of parsimony, hypotheses that postulate fewer entities, causes, and/or processes are better than hypotheses that postulate more. ${ }^{9}$

\footnotetext{
${ }^{7}$ Note that this is different from saying that curve $A$ is more probable, i.e., that $\mathrm{P}($ Curve $A \mid$ Data $)>\mathrm{P}(\mathrm{Curve} B \mid$ Data).

${ }^{8}$ As an anonymous reviewer helpfully pointed out, the assumption that smoothness is simpler than bumpiness can be operationalized in several ways. For example, the degree of a polynomial can be taken to indicate the number of bumps of the associated graph, in which case, a low degree is preferable to a high degree polynomial. As Armitage et al (2002, p. 378) put it: "Considerations of simplicity suggest that as low an order as possible should be used; for example, we should normally use linear regression unless there is any particular reason to use a higher-degree polynomial."

${ }^{9}$ See also Sober (2001, p. 14) who calls this variety of simplicity "semantic simplicity."
} 
As a principle of theory choice, then, the principle of parsimony states that, other things being equal, it is rational to prefer a theory that commits us to a limited ontology. More precisely:

(Parsimony) Other things being equal, if $T_{1}$ is more ontologically parsimonious than $T_{2}$, then it is rational to prefer $T_{1}$ over $T_{2}$.

According to this principle, if a theory, $T_{1}$, has all the ontological commitments of a competing theory, $T_{2}$, but $T_{2}$ is also ontologically committed to $F \mathrm{~s}$, whereas $T_{1}$ is not, then $T_{1}$ is more ontologically parsimonious than $T_{2}$. Thus the notion of ontological parsimony is usually cashed out in terms of Quine's notion of ontological commitment. According to Quine (1981, p. 144), $T$ is ontologically committed to $F$ s if and only if $T$ entails that $F$ s exist. ${ }^{10}$

Like (Elegance), (Parsimony) is also a principle of theory choice. That is, (Elegance) states that, of two competing theories, we should choose the syntactically simpler one, other things being equal. Likewise, (Parsimony) states that, of two competing theories, we should choose the semantically simpler one, other things being equal. Einstein is said to have made a similar point by saying that "things should be made as simple as possible, but not simpler." According to Norman (2011, p. 50), what Einstein actually said was that "the grand aim of all science ... is to cover the greatest possible number of empirical facts by logical deductions from the smallest possible number of hypotheses or axioms." Accordingly, simplicity is a relative property; a theory is simple only relative to another competing theory.

Applied to arguments, (Elegance) and (Parsimony) state that, of two competing arguments, we should prefer the simpler one, other things being equal. More explicitly, (Elegance) states that, of two competing arguments, we should choose the syntactically simpler one (i.e., the one with fewer inferences), other things being equal. Likewise, (Parsimony) states that, of two competing arguments, we should choose the semantically simpler one (i.e., the one with fewer premises), other things being equal. With these syntactic, i.e., (Elegance), and semantic or ontological, i.e., (Parsimony), conceptions of simplicity in hand, I now turn to my arguments for the claim that, other things being equal, simpler arguments are better. I outline three arguments in support of this claim: an argument from mathematical proofs, an argument from scientific theories, and an argument from the conjunction rule.

\section{An argument from mathematical proofs}

My first argument for the claim that, other things being equal, simpler arguments are better is an argument from mathematical proofs. The argument runs as follows:

(1.1) If, other things being equal, simpler mathematical proofs are better, then, other things being equal, simpler deductive arguments are better.

(1.2) Other things being equal, simpler mathematical proofs are better.

\footnotetext{
${ }^{10}$ In terms of ontological parsimony, a further distinction is often drawn between qualitative parsimony (the number of types of entities postulated) and quantitative parsimony (the number of individual entities postulated). See Baker (2003).
} 
Therefore,

(1.3) Other things being equal, simpler deductive arguments are better.

In support of (1.2), consider what Russell (1918, p. 60) says about mathematics:

Mathematics, rightly viewed, possesses not only truth, but supreme beauty - a beauty cold and austere, like that of sculpture, without appeal to any part of our weaker nature, without the gorgeous trappings of painting or music, yet sublimely pure, and capable of a stern perfection such as only the greatest art can show. ${ }^{11}$

In general, mathematicians prefer mathematical proofs that are elegant and simple. For example (emphasis added):

Here we want to discuss another bijection proof, due to Joyal, which is less known but of equal elegance and simplicity (Aigner and Ziegler 2004, p. 174).

One proof stands out for its simplicity and elegance. It was found by Ernst Witt in 1931 and combines two elementary ideas towards a glorious finish (Aigner and Ziegler 2004, p. 23). ${ }^{12}$

If mathematicians' preference for simpler proofs is rational, then a preference for simpler deductive arguments more generally is rational as well. Why? Because mathematical proofs are arguments of the genus (Deduction) and species of the same genus usually share most of their properties in common except the property that makes them different species. For example, Homo sapiens, Homo habilis, and Homo erectus are species of the genus Homo. They share most of their properties in common except the property that makes them different species, which is taken to be primarily increased cranial capacity.

If this is correct, then given that mathematical proofs are a species of the genus (Deduction) in virtue of being proofs (i.e., the sort of arguments whose premises, if true, necessitate the truth of the conclusion), it is reasonable to infer that they share most of their properties in common with other arguments of the genus (Deduction), such as the property of being better arguments when simpler than competing arguments. Now, granted that mathematicians prefer simpler proofs, and that their preference for simpler proofs is rational, it is reasonable to infer that, other things being equal, it is rational to prefer simpler arguments of the genus (Deduction).

\footnotetext{
${ }^{11}$ Commenting on Dufour's Argument and Explanation in Mathematics (2013) at the conference of the Ontario Society for the Study of Argumentation (May 22-25, 2013), Aberdein mentions empirical results suggesting that "mathematicians who completed the study expected explanatory proofs to be precise, useful and not intricate. Or, in other words, simple, fruitful, and exact." Available at: http://www.academia.edu/3646529/Commentary_on_Michel_Dufour_Argument_and_explanation_in_mathematics.
}

${ }^{12}$ See also the special issue of Foundations of Science on Mathematical Argumentation (vol. 14, issue 1-2), edited by Aberdein and Dove (2009). For example, according to Coleman (2009, p. 30), "One proof is better than another because it is more elegant, or informative, or shorter, or easier to follow, or less conceptually demanding, or more easily generalisable, or with less fuzzy details, or more direct, or more constructive, or even more novel..." (emphasis added). 
To sum up, my argument in support of premise (1.1) runs as follows:

(1.1a) If $X$ and $Y$ are species of genus $G$, then $X$ and $Y$ share most of their properties in common, except the property that makes them different species.

(1.1b) Mathematical proofs and other deductive arguments are species of the genus (Deduction).

Therefore,

(1.1) If, other things being equal, simpler mathematical proofs are better, then, other things being equal, simpler deductive arguments are better. ${ }^{13}$

With this support for premises (1.1) and (1.2), I submit, the argument from mathematical proofs shows that, other things being equal, simpler arguments of the genus (Deduction) are better.

\section{An argument from scientific theories}

According to Baker (2011), "Many philosophers believe that, other things being equal, simpler theories are better." This seems to be the case especially as far as scientific theories are concerned. For instance, as van Fraassen (1980, p. 87) writes:

When a [scientific] theory is advocated, it is praised for many features other than empirical adequacy and strength: it is said to be mathematically elegant, simple, of great scope, complete in certain respects: also of wonderful use in unifying our account of hitherto disparate phenomena, and most of all, explanatory. ${ }^{14}$

Now, the important question for present purposes is the following: are simpler arguments better (in much the same way that simpler theories are better, other things being equal)? Here is an argument for an affirmative answer to this question:

(2.1) If, other things being equal, simpler scientific theories are better, then, other things being equal, simpler deductive arguments are better.

(2.2) Other things being equal, simpler scientific theories are better.

Therefore,

(2.3) Other things being equal, simpler deductive arguments are better.

\footnotetext{
${ }^{13}$ As an anonymous reviewer helpfully pointed out, (1.1a) is consistent with there being a particular property $F$ of species $X$ but not $Y$, which are both species of genus $G$, that is not the property that makes $X$ and $Y$ different species of $G$. Perelman and Olbrechts-Tyteca call this kind of argument "argument a pari" (as opposed to argument $a$ contrario). According to Perelman and Olbrechts-Tyteca (1969, p. 241), "These arguments deal with the application or nonapplication to another species of the same genus of what can be asserted about some particular species."

${ }^{14}$ It is worth noting that, for van Fraassen, these features are merely pragmatic, not epistemic or truth-conducive. I will return to this point in Section 5.
} 
In support of premise (2.2) consider how, like mathematicians' preference for simpler mathematical proofs, scientists' preference for simpler scientific theories is quite evident from scientific practice. ${ }^{15}$ If scientists' preference for simpler theories is rational, then a preference for simpler arguments more generally is rational as well. Why? Because scientific theories are a species of the genus (Deduction).

To see why scientific theories are a species of the genus (Deduction), note that philosophers of science generally agree that successful scientific theories do not merely describe phenomena but rather explain them. In other words, successful scientific theories are explanations. As Godfrey-Smith (2003, p. 190) puts it:

Science aims to tell us, and often succeeds in telling us, what the world is like. But it is also common to think that science tells us why things happen; we learn from science not just what goes on but why it does. Science apparently seeks to explain as well as describe (emphasis in original).

For example, the Alvarez Asteroid Impact theory is supposed to be an explanation for the K-T extinction. The theory of evolution by natural selection is supposed to be an explanation for biological diversity. The general theory of relativity is supposed to be an explanation for what we call gravity. Now, the obvious question is this: what are explanations? Philosophers of science have proposed several answers. Which answer is the correct one is a matter of debate. ${ }^{16}$ Several philosophical accounts of scientific explanation, however, construe explanations deductively. Take, for example, the unification account of explanation. According to Kitcher (1989, p. 448), "all explanation is deductive." More explicitly, Kitcher argues that an explanation consists of an argument pattern, which is an ordered triple composed of a schematic argument (i.e., a sequence of schematic sentences, where a schematic sentence is a sentence in which non-logical terms have been replaced with letters), a set of filling instructions for each term in the schematic argument (i.e., instructions for filling in the letters in schematic sentences), and a classification of the schematic argument (i.e., a description of the premises, conclusions, and rules of inference used in the schematic argument). ${ }^{17}$

For instance, consider the argument pattern Kitcher (1993, p. 83) labels "Common Descent":

Question: Why do the members of $G, G$ share $P$ ?

Answer:

(1) $G, G^{\prime}$ are descended from a common ancestor $G_{0}$.

(2) $G_{0}$ members had $P$.

\footnotetext{
${ }^{15}$ See, e.g., Baker (2007), Forster and Sober (1994), and Glynn (2010).

${ }^{16}$ For a useful overview of philosophical accounts of scientific explanation, see Woodward (2011).

${ }^{17}$ An earlier account that identifies scientific explanations with deductive arguments is the Deductive-Nomological account (Hempel 1965).
} 
(3) $P$ is heritable.

(4) No factors intervened to modify $P$ along the $G_{0}-G, G_{0}-G^{\text {` }}$ sequences.

Therefore, (5) Members of $G$ and $G^{\wedge}$ have $P$.

As Kitcher (1993, p. 83) explains:

This consists of five schematic sentences. We could equip it with Filling Instructions by requiring that $G, G^{\prime}, G_{0}$ be replaced by names of groups of organisms, and that $P$ be replaced by the name of a trait of organisms. Similarly, the classification would declare that (1)-(4) are premises and that (5) is deduced from them (emphasis added).

If Kitcher is right, then to explain is to derive descriptions of various phenomena by using as few argument patterns as possible. As Kitcher (1989, p. 423) puts it, "Science advances our understanding of nature by showing us how to derive descriptions of many phenomena, using the same pattern of derivation again and again, and in demonstrating this, it teaches us how to reduce the number of facts we have to accept as ultimate" (emphasis added).

To sum up, then, from the following claims:

Scientific theories are explanations.

Explanations are a species of the genus (Deduction).

It follows that

Scientific theories are a species of the genus (Deduction).

If this is correct, then given that scientific theories are a species of the genus (Deduction) in virtue of being derivations (i.e., the sort of arguments whose premises, if true, necessitate the truth of the conclusion), it is reasonable to infer that they share most of their properties in common with other arguments of the genus (Deduction), such as the property of being better arguments when simpler than competing arguments. Now, granted that scientists prefer simpler explanations, and hence simpler scientific theories, and that their preference for simpler theories is rational, it is reasonable to infer that, other things being equal, it is rational to prefer simpler arguments of the genus (Deduction).

To sum up, my argument for premise (2.1) runs as follows:

(2.1a) If $X$ and $Y$ are species of genus $G$, then $X$ and $Y$ share most of their properties in common, except the property that makes them different species.

(2.1b) Scientific theories and other deductive arguments are species of the genus (Deduction).

Therefore,

(2.1) If, other things being equal, simpler scientific theories are better, then, other things being equal, simpler deductive arguments are better. 
With this support for premises (2.1) and (2.2), I submit, the argument from scientific theories shows that, other things being equal, simpler arguments of the genus (Deduction) are better.

Some might object to the argument from scientific theories by insisting that, pace Kitcher, scientific explanations, and hence scientific theories, are not species of the genus (Deduction). They might point out that one form of non-deductive reasoning that is taken to be ubiquitous in scientific practice is Inference to the Best Explanation (IBE), which is a form of argument of the genus (Induction), given that the premises of an IBE, if true, do not guarantee the truth of its conclusion. ${ }^{18}$

In reply, I would like to suggest that this objection actually provides a way to extend the argument from scientific theories to arguments of the genus (Induction) as well. ${ }^{19}$ To see how, consider the general form of IBE (Govier 2010, p. 302):

1. $D$ exists.

2. $H 1$ would explain $D$.

3. $H 1$ would offer the best available explanation of $D$.

Therefore, probably,

4. $H 1$ is true. [Where " $D$ refers to data, and $H 1$ refers to a hypothesis put forward in an attempt to explain that data" (Govier 2010, p. 298). $]^{20}$

The key premise of an IBE, of course, is the third premise. What makes one explanation the best among several competing explanations? Philosophers of science have identified the following epistemic desiderata, the so-called "theoretical virtues," which make one explanation better than others: "accuracy, simplicity, internal and external consistency, breadth of scope, and fruitfulness" (Longino 1995, p. 383). ${ }^{21}$ Notice that one of those theoretical virtues is simplicity, which means that, of two competing explanations, $H 1$ and $H 2$, the simpler one is the best one, other things being equal.

If this is correct, then the third premise of an IBE is true insofar as $H 1$ is simpler than a competing explanation, $H 2$. From this it follows that an IBE for $H 1$ is better than an IBE for $H 2$ insofar as the third premise of the former is true, whereas the third premise of the latter is not. In other words, arguments of the genus (Induction), namely IBEs, are better when the explanations they are arguments for are simpler than competing explanations.

\footnotetext{
${ }^{18}$ On IBE, see Lipton (2004). Cf. Bird (2007) who argues that there is a form of IBE, namely, inference to the only explanation, in which the truth of the premises guarantees the truth of the conclusion.

${ }^{19}$ Thanks to an anonymous reviewer for this point.

${ }^{20}$ Cf. Psillos (2007, pp. 442-443).

${ }^{21}$ Cf. Kuhn (1977, pp. 320-339).
} 
Now, if IBEs are better when the explanations they are arguments for are simpler than competing explanations, and IBEs are a species of the genus (Induction), then it follows that simpler arguments of the genus (Induction) are better by (2.1a). More explicitly:

(2.1a) If $X$ and $Y$ are species of genus $G$, then $X$ and $Y$ share most of their properties in common, except the property that makes them different species.

(3.1) IBEs and other inductive arguments are species of the genus (Induction).

Therefore,

(3.2) If, other things being equal, simpler IBEs are better, then, other things being equal, simpler inductive arguments are better.

With this argument for (3.2), it follows that simpler arguments of the genus (Induction) are better, since, other things being equal, simpler IBEs are better. That is:

(3.2) If, other things being equal, simpler IBEs are better, then, other things being equal, simpler inductive arguments are better.

(3.3) Other things being equal, simpler IBEs are better.

Therefore,

(3.4) Other things being equal, simpler inductive arguments are better.

Given (2.3) and (3.4), then, it follows that simpler arguments are better. That is, of two competing arguments, $A 1$ and $A 2$, if $A 1$ is simpler than $A 2$, then $A 1$ is a better argument than $A 2$. So, from the following claims:

Other things being equal, simpler deductive arguments are better. [(2.3)]

Other things being equal, simpler inductive arguments are better. [(3.4)]

It follows that

Other things being equal, simpler arguments are better.

Accordingly, of two competing arguments, $A 1$ and $A 2$, if $A 1$ is simpler than $A 2$, we should prefer $A 1$ over $A 2$.

\section{An argument from the conjunction rule}

Some might object to the argument from mathematical proofs and the argument from scientific theories by insisting that simplicity - either (Elegance) or (Parsimony) - is a pragmatic, not an epistemic, virtue. For instance, in the philosophy of science, constructive empiricists distinguish between pragmatic and epistemic virtues of scientific theories and argue that simplicity is a pragmatic, not an epistemic, virtue of scientific theories. As van Fraassen (1985, p. 252) writes: 
A person may believe that a certain theory is true and explain that he does so, for instance, because it is the best explanation he has of the facts or because it gives him the most satisfying world picture. This does not make him irrational, but I take it to be part of empiricism to disdain such reasons (emphasis added).

In other words, according to constructive empiricists, pragmatic virtues, like simplicity, are not truth-conducive, unless one holds a metaphysical belief in the simplicity of the world. As empiricists, however, constructive empiricists think that such a metaphysical belief is unwarranted. As van Fraassen (1980, p. 90) puts it, "it is surely absurd to think that the world is more likely to be simple than complicated (unless one had certain metaphysics or theological views not usually accepted as legitimate factors in scientific inference)." Inspired by constructive empiricism, then, some might object to the argument from mathematical proofs and the argument from scientific theories by claiming that principles like (Elegance) and (Parsimony) are not truth-conducive because "it is surely absurd to think that the world is more likely to be simple than complicated" (van Fraassen 1980, p. 90).

Although I have taken the rationality of mathematicians' preference for simpler mathematical proofs and scientists' preference for simpler scientific theories as basic premises in my arguments from mathematical proofs and scientific theories, respectively, I would like to offer another argument for the claim that, other things being equal, simpler arguments are better by way of a response to the aforementioned objection. This argument, if cogent, shows that one can accept that, other things being equal, simpler argument are better, without a commitment to a metaphysical belief in the simplicity of the world, a belief that constructive empiricists find unwarranted.

To introduce this argument, I need to take a short detour through what Tversky and Kahneman (1983) call "the conjunction fallacy" in probability judgments. In their famous study, Tversky and Kahneman (1983) presented the following case to participants:

Linda is 31 years old, single, outspoken, and very bright. She majored in philosophy. As a student, she was deeply concerned with issues of discrimination and social justice, and also participated in anti-nuclear demonstrations.

Which is more probable?

(L1) Linda is a bank teller.

(L2) Linda is a bank teller and is active in the feminist movement.

Most participants choose (L2), even though (L2) is less probable than (L1), given that two conditions must hold in order for (L2) to be true, namely, that Linda is a bank teller and that she is active in the feminist movement, whereas only one of them must hold for (L1) to be true, namely, that she is a bank teller. More generally, for any two events, $A$ and $B, \operatorname{Pr}(A \& B) \leq \operatorname{Pr}(A)$ and $\operatorname{Pr}(A \& B) \leq \operatorname{Pr}(B)$.

Although (L2) is less probable, it appears that most people find (L2) more plausible. As Tversky and Kahneman's study show, an account rich in details often seems more plausible to people, even though the more details the account contains, the less probable it is, since the 
probability of the conjunction of all the details is lower than the probability of each detail (by the conjunction rule). Accordingly, even though it may seem that an account rich in details is more probable, that is not the case. An account rich in details only seems more probable, because it is more plausible, but it is actually less probable, given that the more details the account contains, the less probable it is, since the probability of the conjunction of all the details is lower than the probability of each detail (by the conjunction rule).

Likewise, an argument rich in details (i.e., rich in premises) might seem better than an argument with fewer premises, even though the more details (i.e., more premises) the argument contains, the probability that it is a sound argument (i.e., a valid argument with true premises) is lower, since the probability of the conjunction of all the details (i.e., all the premises) is lower than the probability of each premise (by the conjunction rule). With this understanding of the conjunction rule, and the distinction between probability and plausibility, the following argument from the conjunction rule for the claim that, other things being equal, simpler arguments are better can be made:

(4.1) According to the conjunction rule, for any two competing arguments, $A 1$ with premise $P$, and $A 2$ with premises $P$ and $Q, \operatorname{Pr}(P \& Q) \leq \operatorname{Pr}(P)$ and $\operatorname{Pr}(P \& Q) \leq$ $\operatorname{Pr}(Q)$.

(4.2) Given the conjunction rule, of two competing arguments, it is rational to prefer the simpler one (i.e., the argument with fewer premises), other things being equal.

Therefore,

(4.3) Of two competing arguments, it is rational to prefer the simpler one (i.e., the argument with fewer premises), other things being equal.

In other words, other things being equal, it is rational to prefer simpler arguments, i.e., arguments with fewer premises. If $A 1$ has fewer premises than $A 2$, then we should prefer $A 1$ over $A 2$, other things being equal. The conclusion of this argument from the conjunction rule applies to arguments of the genus (Induction) as well as to arguments of the genus (Deduction) and there is no need to assume "that the world is more likely to be simple than complicated" (van Fraassen 1980, p. 90).

\section{Conclusion}

In this paper, I have argued that, other things being equal, simpler arguments are better. In other words, I have argued that, other things being equal, it is rational to prefer simpler arguments over less simple ones. I have sketched three arguments in support of this claim. According to the first argument, if simpler mathematical proofs are better, other things being equal, then simpler argument of the genus (Deduction) are better, other things being equal. According to the second argument, if simpler scientific theories are better, other things being equal, then simpler arguments of the genus (Deduction) are better, other things being equal. I have extended this argument from scientific theories to arguments of the genus (Induction) as well on the grounds that, if simpler IBEs are better, other things being equal, then simpler arguments of the genus 
(Induction) are better, other things being equal. According to the third argument, the conjunction rule implies that, other things being equal, it is rational to prefer simpler arguments, i.e., arguments with fewer premises.

Admittedly, there are many questions that stem from the aforementioned arguments, which I have not addressed in this paper. For example, how do we rank arguments according to simplicity? How do we distinguish between simplicity of arguments and simplicity of statements that serve as premises and conclusions of arguments? There are more questions that need be addressed, I am sure, but that will have to wait for another occasion. ${ }^{22}$ Far from being a problem, I take this to be a virtue of the arguments put forth in this paper, since, in addition to simplicity, fruitfulness is often considered a theoretical virtue of both mathematical proofs and scientific theories.

\section{Acknowledgments}

I am grateful to Andrew Aberdein and three anonymous reviewers of Argumentation for helpful comments on earlier drafts.

\section{References}

Aberdein, A. and Dove, I. J. (Eds.). (2009). Mathematical Argumentation. Foundations of Science, 14, Issue 1-2, 1-152.

Aberdein, A. (2010). Virtue in Argument. Argumentation, 24, 165-179.

Aberdein, A. (2013). Commentary on Michel Dufour's Argument and Explanation in Mathematics. Ontario Society for the Study of Argumentation (May 22-25, 2013). Available at: http://www.academia.edu/3646529/Commentary_on_Michel_Dufour_Argument_and_ex planation_in_mathematics.

Aigner, M. and Ziegler, G. M. (2004). Proofs from THE BOOK. Third Edition. Berlin: SpringerVerlag.

Armitage, P., Berry, G., and Matthews, J. N. S. (2002). Statistical Methods in Medical Research. $4^{\text {th }}$ Ed. Malden, MA: Blackwell Science.

Baker, A. (2003). Quantitative Parsimony and Explanatory Power. British Journal for the Philosophy of Science, 54, 245-259.

Baker, A. (2007). Occam's Razor in Science: A Case Study from Biogeography. Biology and Philosophy, 22, 193-215.

\footnotetext{
${ }^{22}$ Another important question raised by an anonymous reviewer is the following: Is there a simpler argument than the ones sketched in this paper for the claim that simpler arguments are better? If we allow for zero-premise arguments, then perhaps the simplest argument for the claim that simpler arguments are better is this: simpler arguments are better. It must be noted, however, that zero-premise arguments are said to be valid "when and only when the conclusion is a tautology" (Corcoran 2001, p. 67). The claim that simpler arguments are better may be evident but it doesn't seem to be a tautology.
} 
Baker, A. (2011). Simplicity. In E. N. Zalta (Ed.), The Stanford Encyclopedia of Philosophy (Summer 2011 Edition). http://plato.stanford.edu/entries/simplicity/.

Bird, A. (2007). Inference to the Only Explanation. Philosophy and Phenomenological Research, $74,424-432$.

Coleman, E. (2009). The Surveyability of Long Proofs. Foundations of Science, 14, 27-43.

Copi, I. and Cohen C. (2005). Introduction to Logic. Twelfth Edition. Upper Saddle River, NJ: Prentice Hall.

Corcoran, J. (2001). Second-order Logic. In C. A. Anderson and M. Zelëny (Eds.), Logic, Meaning, and Computation (pp. 61-75). Springer.

Craig, E. (2002). Philosophy: A Very Short Introduction. New York: Oxford University Press.

Danto, A. C. (2005). Nietzsche as Philosopher. New York: Columbia University Press.

Fisher, R. A. (1925). Statistical Methods for Research Workers. Edinburgh: Oliver \& Boyd.

Forster, M and Sober, E. (1994). How to Tell when Simpler, More Unified, or Less Ad Hoc Theories will Provide More Accurate Predictions. British Journal for the Philosophy of Science, 45, 1-36.

Gauch, H. (2003). Scientific Method in Practice. Cambridge: Cambridge University Press.

Glynn, I. (2010). Elegance in Science: The Beauty of Simplicity. New York: Oxford University Press.

Godfrey-Smith, P. (2003). Theory and Reality: An Introduction to the Philosophy of Science. Chicago: University of Chicago Press.

Govier, T. (2010). A Practical Study of Argument. Seventh Edition. Belmont, CA: Wadsworth.

Hempel, C. (1965). Aspects of Scientific Explanation and Other Essays in the Philosophy of Science. New York: Free Press.

Hitchcock, D. (2007). Informal Logic and the Concept of Argument. In D. Jacquette (Ed.), Philosophy of Logic (pp. 101-129). Amsterdam: Elsevier.

Johnson, R. (2000). Manifest Rationality. Mahwah, NJ: Lawrence Erlbaum Associates.

Kelly, T. (2011). Following the Argument Where It Leads. Philosophical Studies, 154, 105-124.

Kitcher, P. (1989). Explanatory Unification and the Causal Structure of the World. In P. Kitcher and W. Salmon (Eds.), Scientific Explanation (pp. 410-505). Minneapolis: University of Minnesota Press.

Kitcher, P. (1993). The Advancement of Science: Science Without Legend, Objectivity Without Illusions. New York: Oxford University Press.

Kuhn, T. S. (1977). Objectivity, Value Judgment, and Theory Choice. In The Essential Tension: Selected Studies in Scientific Tradition and Change (pp. 320-339). Chicago: The University of Chicago Press.

LeBon, T. (1999). Philosophy and the Perils of Popularisation. Practical Philosophy, 2, 15-17.

Lipton, P. (2004). Inference to the Best Explanation. Second Edition. London: Routledge.

Longino, H. E. (1995). Gender, Politics, and the Theoretical Virtues. Synthese, 104, 383-397.

McKeon, M. (2013). Argument. In J. Fieser and B. Dowden (Eds.), Internet Encyclopedia of Philosophy (May 2013). http://www.iep.utm.edu/argument/.

Mellor, D. H. (2005). Probability: A Philosophical Introduction. New York: Routledge.

Norman, D. A. (2011). Living with Complexity. Cambridge, MA: The MIT Press.

Perelman, C. and Olbrechts-Tyteca, L. (1969). The New Rhetoric: A Treatise on Argumentation. J. Wilkinson and P. Weaver (trans.). Notre Dame: University of Notre Dame Press.

Protevi, J. (2001). Political Physics. New York: The Athlone Press. 
Psillos, S. (2007). The Fine Structure of Inference to the Best Explanation. Philosophy and Phenomenological Research, 74, 441-448.

Quine, W. V. O. (1981). Theories and Things. Cambridge, MA: Harvard University Press.

Russell, B. (1918). Mysticism and Logic. London: Longmans, Green, and Co.

Sinnott-Armstrong, W. and Fogelin, R. (2010). Understanding Arguments: An Introduction to Informal Logic. Eighth Edition. Belmont, CA: Wadsworth.

Sober, E. (1988). Reconstructing the Past: Parsimony, Evolution and Inference. Cambridge, MA: MIT Press.

Sober, E. (1994). Let's Razor Ockham's Razor. In E. Sober (Ed.). From a Biological Point of View (pp. 136-157). Cambridge: Cambridge University Press.

Sober, E. (1998). Simplicity (in scientific theories). In E. Craig (Ed.). Routledge Encyclopedia of Philosophy (pp. 780-783). Volume 8. London: Routledge.

Sober, E. (2001). What is the Problem of Simplicity? In A. Zellner, H. Keuzenkamp, \& M. McAleer (Eds.). Simplicity, Inference, and Modeling: Keeping it Sophisticatedly Simple (pp. 13-31). Cambridge: Cambridge University Press.

Tversky, A. and Kahneman, D. (1983). Extensional versus Intuitive Reasoning: The Conjunction Fallacy in Probability Judgment. Psychological Review, 90, 293-315.

van Fraassen, B. C. (1980). The Scientific Image. New York: Oxford University Press.

van Fraassen, B. C. (1985). Empiricism in the Philosophy of Science. In P. M. Churchland and C. A. Hooker (Eds.), Images of Science: Essays on Realism and Empiricism (pp. 245-308). Chicago: University of Chicago Press.

Walton, D. (1996). Argument Structure: A Pragmatic Theory. Toronto: University of Toronto Press.

Wood, A. W. (2004). Karl Marx. $2^{\text {nd }}$ Edition. New York: Routledge.

Woodward, J. (2011). Scientific Explanation. In E. N. Zalta (Ed.), The Stanford Encyclopedia of Philosophy (Winter 2011 Edition). http://plato.stanford.edu/entries/scientific-explanation/. 